\title{
PEMBUATAN MEDIA KOMUNIKASI MENGGUNAKAN MOTION GRAPHIC UNTUK SOSIALISASI JOB FAMILY PADA BANK INDONESIA
}

\author{
Fairuz Siregar \\ Teknik Multimedia dan Jaringan \\ Politeknik Negeri Jakarta \\ fairuzsiregar@gmail.com
}

\begin{abstract}
Abstrak
Artikel ini bertujuan untuk memberikan gambaran sosialisasi Job Family melalui pembuatan motion graphic sebagai media komunikasi berbasis video yang unik dan mudah dipahami oleh pegawai Bank Indonesia. Manfaat dari sosialisasi Job Family menggunakan motion graphic ini adalah terciptanya pengetahuan dasar tentang kebijakan Job Family sehingga, selanjutnya pegawai akan tertarik untuk mengetahui lebih lanjut tentang jalur karier, pengembangan karier serta peran dan fungsi pegawai berdasarkan Job Family. Metode yang diterapkan dalam penelitian ini adalah metode Luther, yang meliputi tahapan Concept; Design, Material Collecting, Assembly, Testing, dan Distribution. Berdasarkan paparan pembuatan media komunikasi untuk sosialisasi Job Family menggunakan motion graphic, dapat disimpulkan bahwa video motion graphic menjadi salah satu terobosan baru dari berbagai media komunikasi yang digunakan dalam rangka sosialisasi. Motion graphic yang telah dibuat berdurasi 1 menit 28 detik dengan format video mp4 yang memiliki kapasitas ukuran sebesar 49 MB dengan menggunakan perangkat lunak Adobe After Effect CS6. Motion graphic ini tersusun dari 6 scene dan 1 musik latar. Motion graphic media komunikasi untuk sosialisasi Job Family ini dibuat dengan durasi yang singkat dan materi yang padat, sehingga dapat mudah dimengerti dan dipahami.
\end{abstract}

Kata Kunci: motion graphic, sosialisasi job family

\begin{abstract}
The aim of this paper is to provide an overview of Job Family socialization by making motion graphic video as the communication media which is unique and easy to understand by Indonesian Bank employees. The advantage of using this Job Family motion graphic are to get basic knowledge about Job Family policy then the employees would be interested to know more about carrier path, carrier development and also the role and function of employee based on Job Family. the method used in this research is Luther, which involves the stage of Concept; Design, Material Collecting, Assembly, Testing, dan Distribution. According to these studies, The conclusion of this research is motion graphic video could be the one of communication media breakthrough for socialization. The motion graphic video are made by Adobe After Effect CS6. The duration of this 49 Megabytes video are 1 minute 28 seconds with Mp4 format. It is contains 6 scenes with backsound. That short duration contains congested content so that it easy to understand.
\end{abstract}

Keywords: motion graphic, job family socialization 


\section{PENDAHULUAN}

\section{Latar Belakang}

Perkembangan teknologi dalam penyampaian informasi berkembang dengan sangat pesat hingga saat ini. Faktanya membuktikan bahwa banyak sekali inovasi teknologi terkait penyajian informasi, salah satunya adalah motion graphic. Motion graphic merupakan alternatif tayangan video yang kini marak digunakan diberbagai media, baik televisi, internet, bahkan dalam presentasi perusahaan dan lembaga negara. Pemanfaatan motion graphic oleh berbagai perusahaan dan lembaga negara sebagai media presentasi informasi dianggap dapat memberikan daya tarik tersendiri. Representasi dari penggunaan motion graphic sebagai sarana penyampaian informasi oleh perusahaan serta lembaga negara dapat dilihat pada beberapa digital billboard yang terpasang disepanjang jalan ibukota Jakarta. Salah satu lembaga negara yang telah memanfaatkan motion graphic sebagai sarana penyampaian informasi adalah Bank Indonesia.

Bank Indonesia adalah lembaga negara yang independent. Bank Indonesia sedang mengamati salah satu visinya, yaitu menjadi bank sentral terbaik dan kredibel pada tahun 2024. Membangun kapabilitas dengan mengembangkan potensi terbaik dari sumber daya manusia yang dimilikinya menjadi sebuah keharusan guna pengelolaan karier setiap pegawai. Bank Indonesia juga telah membuat suatu kebijakan terkait pengelompokan jabatan berdasarkan kesamaan fungsi yang akan menjadi koridor pergerakan karier pegawai. Kebijakan tersebut disebut dengan istilah $\mathrm{Job}$ Family. Job Family merupakan sekelompok jabatan yang memiliki kesamaan karakteristik inti seperti peran dan fungsi. Dengan adanya pengelompokan berdasarkan Job Family akan mensinergikan kebutuhan organisasi dengan aspirasi karier pegawai sehingga terbentuk kapabilitas pegawai yang optimal dalam proses pengembangan kariernya. Akan tetapi, masih banyak pegawai Bank Indonesia yang belum mengetahui adanya pengelompokan berdasarkan $J o b$ Family serta manfaatnya bagi pengembangan karier mereka.

Untuk mengatasi masalah ini, maka harus dibuat sebuah media komunikasi yang dapat mensosialisasikan pengelompokan berdasarkan Job Family di Bank Indonesia. Ada berbagai macam cara untuk membuat media komunikasi, salah satunya adalah penjelasan rinci melalui majalah internal dan situs Bank Indonesia. Namun, media komunikasi tersebut memuat terlalu banyak tulisan/text sehingga dianggap kurang efektif dan kurang menarik. Oleh karena itu dibutuhkan suatu media komunikasi lain yang lebih efektif dan lebih menarik untuk dipelajari.

Untuk itulah media komunikasi dengan motion graphic dipilih sebagai salah satu media komunikasi yang efektif dan menarik karena tidak memuat terlalu banyak text, melainkan campuran gambar, warna, suara, dan motion. Berdasarkan uraian penulis diatas, penulis mengangkat tema laporan Praktik Kerja Lapangan dengan judul "Pembuatan Media Komunikasi Menggunakan Motion graphic untuk Sosialisasi Job Family pada Bank Indonesia". Penulis berharap dengan pengenalan Job Family menggunakan motion graphic dapat bermanfaat dalam penyajian informasi kepada seluruh pegawai di Bank Indonesia serta calon pegawai Bank Indonesia. Penulis juga berharap laporan ini dapat berguna bagi pengembangan ilmu Teknologi Informatika dan Komputer khususnya di Jurusan Teknik Informatika dan Komputer Politeknik Negeri Jakarta. 


\section{Perumusan Masalah}

Berdasarkan identifikasi masalah yang ada, maka dapat disimpulkan ringkasan masalah sebagai berikut :

1. Bagaimana membuat suatu media komunikasi yang memuat materi ringan sehingga dapat menyampaikan adanya kebijakan terkait pemetaan pegawai berdasrkan Job Family?

2. Bagaimana cara mensosialisasikan kebijakan Job Family dengan teknik yang menarik serta mudah dipahami oleh pegawai maupun calon pegawai Bank Indonesia?

\section{Batasan Masalah}

Dari rumusan masalah diatas penulis membatasi permasalah yang akan dibahas yaitu dengan batasan masalah sebagai berikut :

1. Pembuatan media komunikasi informasi dasar terkait Job Family.

2. Pembuatan suatu media komunikasi dengan teknik motion graphic yang unik, menarik serta mudah dipahami oleh pegawai maupun calon pegawai.

\section{Tujuan dan Manfaat}

Tujuan

Tujuan dari pembuatan motion graphic ini adalah menyediakan media komunikasi berbasis video yang unik dan mudah dipahami oleh pegawai Bank Indonesia..

\section{Manfaat}

Manfaat dari sosialisasi Job Family menggunakan motion graphic ini adalah terciptanya pengetahuan dasar tentang kebijakan Job Family sehingga, selanjutnya pegawai akan tertarik untuk mengetahui lebih lanjut tentang jalur karier, pengembangan karier serta peran dan fungsi pegawai berdasarkan Job Family.

\section{Metode Penyelesaian Masalah}

Metode yang diterapkan dalam pembuatan skripsi adalah metode Luther, dimana metode ini meliputi tahap - tahap sebagai berikut:

1. Concept

Menentukan tujuan dan siapa pengguna program (identification audience), tujuan aplikasi (informasi, hiburan, pelatihan, dan lain-lain, dan spesifikasi umum.

2. Design

Tahap dalam membuat spesifikasi secara rinci mengenai arsitektur program, gaya, tampilan dan kebutuhan material atau bahan untuk program.

3. Material Collecting

Tahap pengumpulan bahan yang sesuai dengan kebutuhan yang dikerjakan. Bahan-bahan tersebut, antara lain gambar icon, foto, animasi, video, audio.

4. Assembly

Tahap pembuatan semua objek atau bahan multimedia.

5. Testing

Tahap testing (pengujian) dilakukan setelah menyelesaikan tahap assembly.

6. Distribution

Tahap akhir pengemasan dan penyebaran dari produk.

\section{Tinjauan Pustaka}

Job Family

Michael Amstrong dalam bukunya Employee Reward menjelaskan bahwa Job Family ialah sekelompok jabatan pekerjaan yang memiliki lingkup dan tujuan yang sama tetapi, memiliki tingkatan pekerjaan berbeda. Job Family juga dapat didefinisikan sebagai kumpulan dari pekerjaan yang memiliki karakteristik dan konten serupa berdasarkan analisa pekerjaan. Suatu Job Family akan berbeda dengan Job Family lainnya tergantung pada tingkat pengetahuan, 
kemampuan serta kompetensi yang dibutuhkan dalam satu pekerjaan. Setelah terbentuknya Job Family pada setiap level pekerjaan, maka pemetaan level berdasarkan kompetensi dan kemampuan dapat terdefinisi. Job Family juga akan memberikan gambaran yang jelas terkait career path pegawai. Maka dalam manajemen orientasi pegawai berdasarkan Job Family perlu dilakukan pemantauan dan kontrol (Sudhir Andrews) Pengelompokan berdasarkan Job Family tidak memiliki metode yang pasti dan konsisten, sehingga setiap organisasi dapat merancang definisi terkait $\mathrm{Job}$ Family yang sesuai dengan kebutuhan dan keadaan masing-masing organisasi.

\section{Bank Indonesia}

Bank Indonesia atau bank sentral republik Indonesia merupakan lembaga independen yang berada diluar pemerintahan. Bank Indonesia memiliki fungsi utama dalam mencapai dan memelihara kestabilan nilai rupiah terhadap barang dan jasa serta terhadap mata uang negara lain. Sebagai bank sentral, Bank Indonesia memiliki visi untuk menjadi bank sentral terbaik dan kredibel di kawasan regional pada tahun 2024. Kinerja yang baik serta kompetensi yang matang pada setiap individu dalam organisasi, dibutuhkan untuk mencetak para ahli dalam setiap bidang yang mampu mengarahkan Bank Indonesia untuk mencapai misi tersebut. Kinerja organisasi di Bank Indonesia akan menjadi lebih optimal ketika proses bisnis dijalankan dengan efektif dan tiap individu mampu menunjukan kemampuan terbaiknya. Bank Indonesia menghadapi kondisi ini dengan membentuk suatu kebijakan yang menempatkan pegawai berdasarkan Job Family yang sesuai dengan potensi terbaik pegawai, guna memaksimalkan kinerja tiap individu atau proses people to job fit ( Fokus Bank Indonesia 33 ).

\section{Media Komunikasi}

Kata media berasal dari bahasa latin medius dan merupakan bentuk jamak dari medium yang berarti perantara atau pengantar. Sebagai sebuah perantara, media tidak selalu berhasil memberitahu apa yang kita pikir, tetapi media benarbenar berhasil memberitahu kita berpikir tentang apa (Bernard Cohen dalam Stanley J. Baran dan Dennis K. Davis, 2010:347). Media akan mengarahkan kita pada apa yang harus kita lakukan. Media juga memberikan berbagai gagasan, sedangkan masyarakat akan mengikutinya. Asumsi dari teori ini adalah media mempunyai kemampuan untuk menyeleksi dan mengarahkan perhatian masyarakat pada gagasan tertentu. Media mengatakan pada kita apa yang penting dan apa yang tidak penting (Nurudin, 2007:196).

Sedangkan kata komunikasi berasal dari bahasa latin communicatio yang berarti pemberitahuan atau pertukaran pikiran (Drs.Tommy Suprapto,M.S.). Menurut pendapat William Albig, komunikasi merupakan proses sosial yang menggambarkan pelemparan pesan yang mau tidak mau akan menumbuhkan pengaruh pada semua proses dan berakibat pada bentuk perilaku manusia. Secara umum merupakan suatu proses pembentukan, penyampaian, penerimaan dan pengolahan pesan yang terjadi di dalam diri seseorang dan atau di antara dua atau lebih dengan tujuan tertentu.

Sehingga media komunikasi dapat diartikan sebagai sebuah perantara atau sarana penyampaian pesan yang dapat ditujukan kepada masyarakat maupun kepada individu guna menanamkan ide, gagasan ataupun sikap dengan tujuan mutual understanding.

\section{Sosialisasi}

Sosialisasi adalah semua proses dimana individu dibentuk oleh sistem sosialnya ketika mereka tumbuh dan 
berkembang (Eccles, 1995:164). Sedangkan, menurut vincentius satu sosialisasi merupakan suatu proses belajar seorang anggota masyarakat untuk mengenal kebudayaan atau nilai yang ada disekitarnya. Melalui sosialisasi, seorang individu diupayakan untuk menjadi sosok manusia yang diharapkan. Sedangkan proses sosialisasi menurut Waluyo dalam buku yang dikutip dari Prof.Dr MZ Lawang (1985) adalah suatu proses yang mempelajari norma, nilai, peran dan semua persyaratan lain yang diperlukan seorang individu untuk berpartisipasi secara efektif dalam kehidupan sosial. Melalui proses sosialisasi seorang individu memiliki kemampuan untuk beradaptasi dan menjadi lebih mandiri.

Dari penjelasan di atas penulis menyimpulkan bahwa sosialisasi memiliki peran penting untuk semua individu khususnya dalam organisasi. Sosialisasi merupakan suatu proses dimana seorang individu dalam organisasi akan mengadaptasi nilai atau kultur dalam organisasi. Sosialisasi bermanfaat dalam pembelajaran mengenai peran individu dalam organisasi sehingga nantinya masing-masing individu dapat menempatkan diri dengan baik dalam suatu organisasi karena sudah memahami dan mengenali lingkungan organisasi tersebut.

\section{Motion Graphic}

Banyak orang berpendapat bahwa motion graphic merupakan bagian dari animasi. Sebenarnya motion graphic dan animasi merupakan dua hal yang berbeda. Michael Sega Gumelar dalam bukunya yang berjudul Academic Writing menyatakan bahwa banyak orang yang salah dalam memproduksi animasi sehingga menghasilkan motion graphic namun, sejatinya motion graphic bukanlah animasi. Animasi dibuat berdasarkan prinsip-prinsip gerak yang ada di alam atau prinsip fisika. Implementasi hukum fisikalah yang membedakan antara animasi dengan motion graphic. Motion graphic pada umumnya merupakan gabungan dari potongan-potongan desain atau animasi berbasis media visual yang Seperti 2D, 3D, video, film, tipografi, ilustrasi, fotografi, dan musik (Krishna, et al., 2010).

Motion graphic atau motion grafis adalah istilah yang digunakan untuk menggambarkan berbagai solusi desain grafis profesional dalam menciptakan suatu desain komunikasi yang dinamis dan efektif. Dunia perdagangan, informasi dan hiburan adalah suatu tantangan, ketika audience memutuskan kesuksesan suatu tayangan. Maka dari itulah diperlukan strategi, kreativitas, dan keterampilan dari seorang broadcaster dan animator dalam seni motion graphic. (Curran, 2000)

Dari penjelasan di atas, maka penulis dapat menyimpulkan bahwa motion graphic dan animasi memiliki tujuan yang berbeda. Motion graphic yang hadir dengan sajian potongan grafis akan memiliki tujuan akhir untuk lebih mengkomunikasikan informasi dan desain visual. Sedangkan animasi yang lahir dari ilustrasi fisik akan bertujuan untuk menampilkan pesan-pesan implisit yang terdapat dalam cerita serta digambarkan dengan emosi karakterkarakter yang bergerak.

\section{METODE PENELITIAN}

\section{Concept}

Pada tahap ini dirumuskan dasardasar dari proyek yang akan dikerjakan. Kegiatan yang dilakukan, antara lain menganalisa siapa yang akan menjadi target audience, merumuskan tujuan utama pembuatan motion graphic, menganalisa bagaimana kesan yang akan ditampilkan kepada audience dll. Selanjutnya dilakukan pembuatan brief dari hasil brainstorming. Brief tersebut 
yang kemudian dijadikan sebagai acuan pembuatan storyboard untuk motion graphic Job Family yang akan dikerjakan.

Perancangan storyline dilakukan dengan metode problem and solution untuk mengenalkan kebijakan Job Family. Penulis mencoba menjelaskan permasalahan yang dihadapi sebelum dibentuk Job Family, kemudian menjelaskan bagaimana Job Family akan menjadi suatu solusi nyata yang dapat diimplementasikan di Bank Indonesia. Berikut adalah tabel ringkasan spesifikasi produk dari tahap konsep.

Tabel 3.1 Spesifikasi Produk

\begin{tabular}{|l|l|}
\hline Judul & $\begin{array}{l}\text { Job Family Pada Bank } \\
\text { Indonesia }\end{array}$ \\
\hline Durasi & $\begin{array}{l}\text { Kurang dari sama dengan 2 } \\
\text { menit }\end{array}$ \\
\hline Tujuan & $\begin{array}{l}\text { Mengenalkan kebijakan Job } \\
\text { Family dengan media }\end{array}$ \\
\hline
\end{tabular}

\begin{tabular}{|l|l|}
\hline & $\begin{array}{l}\text { komunikasi yang unik dan } \\
\text { menarik }\end{array}$ \\
\hline Audiens & $\begin{array}{l}\text { Pegawai/Eksternal 20 - 50 } \\
\text { Tahun }\end{array}$ \\
\hline $\begin{array}{l}\text { Output } \\
\text { (Hasil } \\
\text { Akhir) }\end{array}$ & $\begin{array}{l}\text { Video Motion Graphic } \\
(. \mathrm{mp} 4)\end{array}$ \\
\hline
\end{tabular}

\section{Design}

Tahap desain dalam pembuatan motion graphic ini dilakukan secara spesifik, storyline yang telah dibuat selanjutnya divisualisasikan dalam bentuk gambar, rancangan tersebut disebut storyboard. Storyboard akan menampilkan seluruh gambaran material dan menampilkan setiap scene dari motion graphic untuk sosialisai Job Family di Bank Indonesia. Gambar 3.1 berikut ini merupakan storyboard dari pembuatan motion graphic Job Family.

Tabel 3.2 Storyboard

\begin{tabular}{|c|c|c|}
\hline No & Gambar & Deskripsi \\
\hline 1 & & $\begin{array}{l}\text { Scene1_bumperJF : Menampilkan logo, judul, sedikit } \\
\text { keterangan mengenai makna Job Family. } \\
\text { Teknik yang digunakan: scale, opacity, bounce, trim path, } \\
\text { rotation, position. }\end{array}$ \\
\hline 2 & & $\begin{array}{l}\text { Scene2_kenapaJF : Menampilkan pertanyaan mengapa } \\
\text { Family diperlukan. } \\
\text { Teknik yang digunakan: magnify, masking, position, bulge, } \\
\text { parent object, curves effect, exposure, distort. }\end{array}$ \\
\hline 3 & 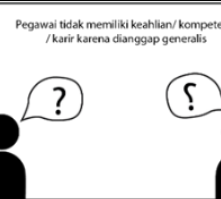 & $\begin{array}{l}\text { Scene3_sebelumJF: Keadaan sebelum diterapkan kebijakan } \\
\text { Job Family. } \\
\text { Teknik yang digunakan: position, scale, rotation, parent } \\
\text { object. }\end{array}$ \\
\hline 4 & & $\begin{array}{l}\text { Scene3_sequence } 2 \text { : Keadaan sebelum diterapkan kebijakan } \\
\text { Job Family. } \\
\text { Teknik yang digunakan: position \& text effect. }\end{array}$ \\
\hline 5 & 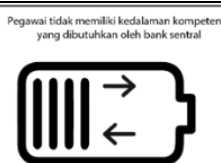 & $\begin{array}{l}\text { Scene4_akibat : Menggambarkan akibat dari tidak } \\
\text { terpetakan nya pegawai bank sentral. } \\
\text { Teknik yang digunakan: position \& opacity. }\end{array}$ \\
\hline
\end{tabular}




\begin{tabular}{|l|l|l|}
\hline 6 & $\begin{array}{l}\text { Scene4_sequence2 : Menggambarkan akibat dari tidak } \\
\text { terpetakan nya pegawai bank sentral. } \\
\text { Teknik yang digunakan: masking, position, rotation \& } \\
\text { opacity. }\end{array}$ \\
\hline 9 & $\begin{array}{l}\text { Scene5_5JF : Bank Indonesia memiliki 5 Job Family. } \\
\text { Teknik yang digunakan: position \& scale. }\end{array}$ \\
\hline 8 & $\begin{array}{l}\text { Scene5_5JF : Bank Indonesia memiliki 5 Job Family. } \\
\text { Teknik yang digunakan: opacity. }\end{array}$ \\
\hline 10 & $\begin{array}{l}\text { Scene6_manfaatJF : Menggambarkan pegawai yang fokus } \\
\text { pada suatu bidang atau kompetensi. } \\
\text { Teknik yang digunakan: CC Sphere effect, scale, opacity, } \\
\text { rotation, parent object. }\end{array}$ \\
\hline 11 & $\begin{array}{l}\text { Scene6_manfaatJF : Akan terbentuk sebuah personal } \\
\text { branding bagi tiap-tiap pegawai. } \\
\text { Teknik yang digunakan: scale, opacity, rotation, parent } \\
\text { object, text effect. }\end{array}$ \\
\hline
\end{tabular}

\section{Material Collecting}

Pada tahap ini, dikumpulkan material-material yang dibutuhkan pada saat pembuatan motion graphic Job Family. Material-material yang dikumpulkan berupa gambar, icon dengan ekstensi png, backsound (suara latar), video footage, rekaman wawancara terkait Job Family serta dokumen perusahaan yang berkaitan dengan $J o b$ Family. Sebagian besar material didapatkan dari pihak Bank Indonesia dan diunduh dari internet. Berikut sebagian daftar material yang digunakan dalam pembuatan motion graphic ini.

\begin{tabular}{|c|c|c|c|c|}
\hline No. & Material & Nama & Ekstensi File & Keterangan \\
\hline 1. & & LogoBI & PNG & Gambar vektor \\
\hline 2. & & BumperBI & AEP & $\begin{array}{l}\text { File footage After } \\
\text { Effect }\end{array}$ \\
\hline 3. & & Loupe & PNG & Gambar vektor \\
\hline 4. & & OrangMikir & AI & Gambar vektor \\
\hline 5. & & Tools & PNG & $\begin{array}{l}\text { Gambar vektor } \\
\text { Sumber : } \\
\text { freepik.com }\end{array}$ \\
\hline 6. & & OrganisasiRugi & PROJ & $\begin{array}{l}\text { File footage Adobe } \\
\text { Premiere }\end{array}$ \\
\hline
\end{tabular}

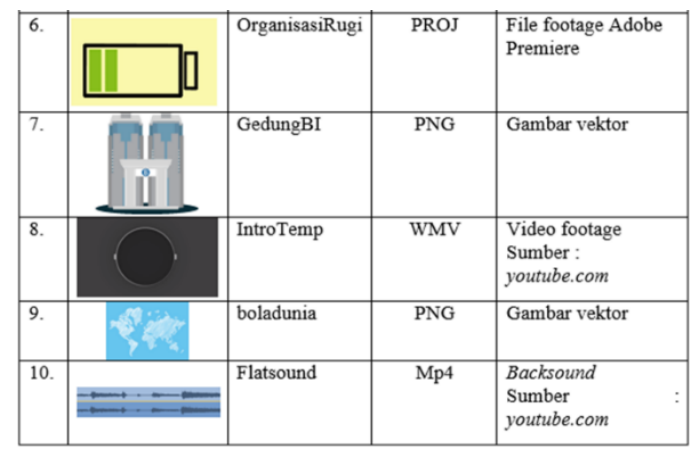

\section{Assembly}

Pada tahap ini, dilakukan proses pembuatan motion graphic berdasarkan storyboard yang telah dibuat dan material yang telah dikumpulkan pada tahap sebelumnya. Pada proses pembuatan motion graphic ini, pembuatan dibagi menjadi 4 tahap, yaitu tahap designing, animating, compositing (penggabungan) dan rendering.

\section{Designing}

Tahap designing merupakan proses pembuatan visual objek-objek yang menjadi material inti pembuatan 
motion graphic ini. Dilakukan proses pembuatan beberapa elemen yang dibutuhkan sesuai sketsa grafis yang telah tergambar pada storyboard yang telah dibuat sebelumnya. Berikut adalah gambar proses tahap designing.

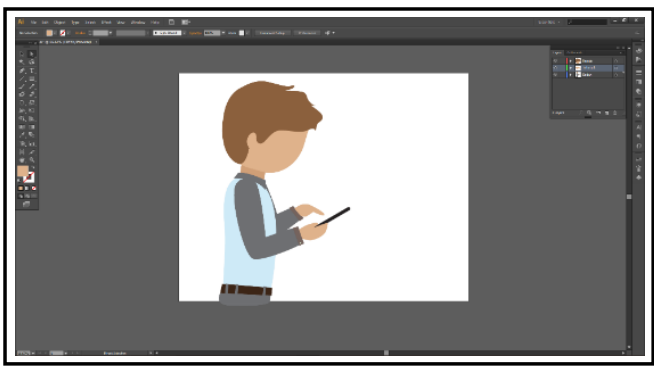

Gambar 3.3 Tampilan Proses Designing

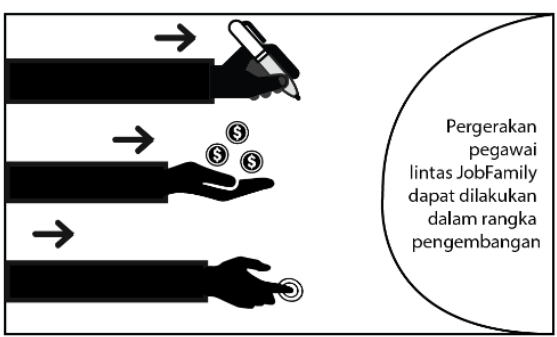

Gambar 3.4 Tampilan Navigasi Credit

\section{Animating}

Animating merupakan proses menggerakan objek-objek still image agar terlihat seolah memiliki ilusi pergerakan. Proses animating untuk setiap scene memiliki teknik dasar yang relatif sama, yaitu menggunakan opacity, scale, position dan rotation. Penulis juga menggunakan beberapa effect dari Adobe After Effect CS6 pada beberapa scene, diantaranya $c c$ sphere, transition, masking, magnify, dll. Berikut adalah gambaran proses animating. Selanjutnya video setiap scene memasuki proses render motion graphic per scene. Gambar 3.4 menunjukan proses tahapan animasi.

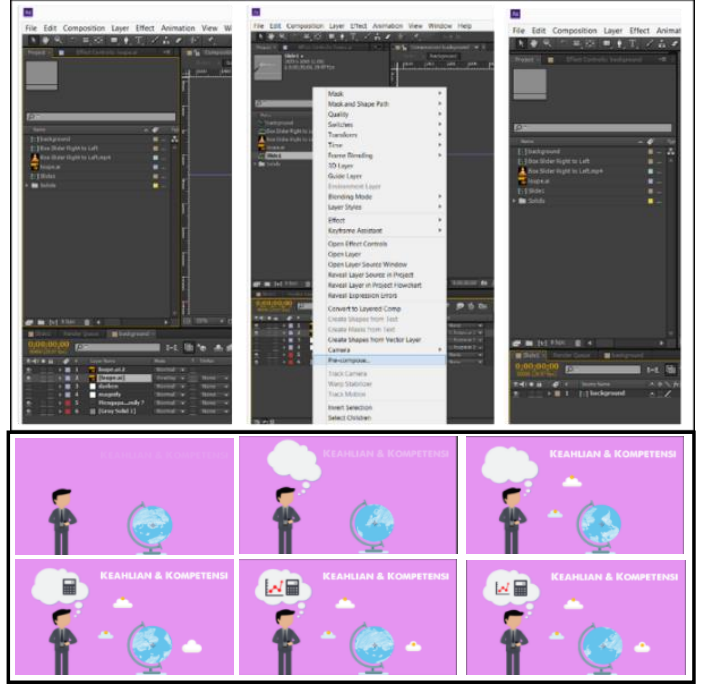

Gambar 3.5 Proses Tahap Animating

\section{Compositing (Penggabungan)}

Setelah seluruh scene telah melalui proses render di Adobe After Effect CS6, proses selanjutnya adalah compositing. Proses ini dilakukan untuk menggabungkan seluruh video hasil render pada proses animating yang telah dilakukan sebelumnya. Perangkat lunak yang digunakan dalam proses compositing adalah Adobe Premiere CS6. Selanjutnya, semua video-video dari hasil render sebelumnya di import kedalam panel project seperti gambar $3.17 \mathrm{di}$ bawah ini.

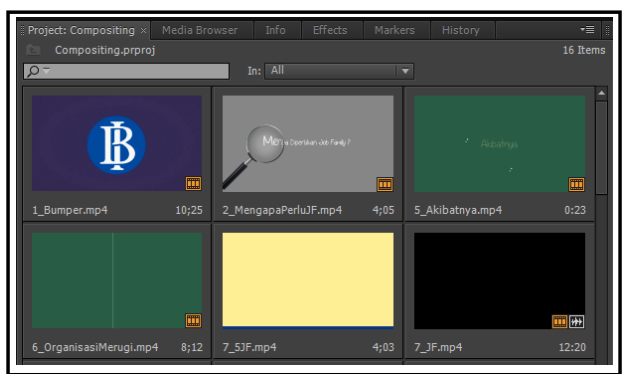

Gamber 3.6 Contoh Script Idiom in Melodies

\section{Rendering}

Rendering pada Adobe Premiere CS6 merupakan proses terakhir yang dilakukan penulis untuk menghasilkan motion graphic sosialisasi Job Family. Rendering adalah proses export/ pengolahan akhir dari berbagai format 
file yang ada dalam composition Adobe Premiere menjadi format video.

\section{Testing}

Pada tahap testing, dilakukan pengujian kembali hasil video yang telah dibuat. Pada tahap pengujian pertama, dilakukan dengan cara meninjau kembali hasil video yang telah dibuat untuk menekan adanya kemungkinan crash, broken maupun incomplete. Selanjutnya, testing dilakukan dengan penayangan hasil video kepada rekan-rekan DSDM untuk menguji apakah motion graphic yang dibuat menarik dan mudah dipahami.

\section{Distribution}

Pada tahap distribution, dilakukan proses kompresi kembali video yang telah dibuat agar proses distribusi lebih efisien, selanjutnya file dipindahkan dari perangkat komputer ke dalam usb flash drive untuk keperluan dokumentasi Bank Indonesia.

\section{SIMPULAN}

Berdasarkan paparan pembuatan media komunikasi untuk sosialisasi Job Family menggunakan motion graphic, dapat disimpulkan bahwa video motion graphic menjadi salah satu terobosan baru dari berbagai media komunikasi yang digunakan dalam rangka sosialisasi. Motion graphic yang telah dibuat berdurasi 1 menit 28 detik dengan format video mp4 yang memiliki kapasitas ukuran sebesar 49 MB dengan menggunakan perangkat lunak Adobe After Effect CS6. Motion graphic ini tersusun dari 6 scene dan 1 musik latar. Motion graphic media komunikasi untuk sosialisasi Job Family ini dibuat dengan durasi yang singkat dan materi yang padat, sehingga dapat mudah dimengerti dan dipahami.
Motion graphic komunikasi untuk sosialisasi Job Family sudah melalui beberapa tahap review and testing. Penulis menampilkan hasil video kepada rekan-rekan DSDM, pembimbing industri dan juga pegawai baru yang awam dan belum mengetahui kebijakan Job Family. Setelah melalui tahap-tahap pengujian tersebut, penulis menerima feedback positif karena mereka memahami isi materi dari motion graphic ini, mereka juga sangat atraktif dengan penggunaan warna dan desain yang digunakan oleh penulis untuk membuat video motion graphic ini.

Pembuatan motion graphic untuk sosialisasi Job Family ini diharapkan dapat menginformasikan pengelompokan fungsi pegawai berdasarkan Job Family di Bank Indonesia. Dalam pembuatan motion graphic ini, masih terdapat banyak kekurangan serta terdapat banyak hal yang bisa dikembangkan, oleh karena itu penulis memberikan beberapa saran. Berikut beberapa saran yang dapat penulis sampaikan setelah menjalani Praktik Kerja Lapangan:

1. Dalam tahap concept, disarankan untuk melakukan brainstorming, sehingga akan tercipta lebih banyak ide yang dapat dikembangkan.

2. Dalam tahap design, disarankan untuk membuat sebuah visual storyboard dengan rincian yang jelas. Desainer motion graphic juga disarankan untuk lebih banyak membaca dan mencari referensi untuk mempermudah tahap pembuatan storyboard. Storyboard yang dibuat, disarankan untuk lebih detail. Mulai dari komposisi, pergerakan, audio, hingga teks yang akan ditampilkan agar mempermudah client untuk membaca dan membayangkan storyboard sehingga akan mengurangi adanya kesalahan persepsi. 
3. Dalam tahap material collecting, disarankan untuk mencari lebih banyak data terkait informasi yang dibutuhkan dalam pembuatan motion graphic. Gunakan objek atau still image dengan jumlah seminimal mungkin agar informasi yang disampaikan lebih jelas.

4. Dalam tahap assembly, disarankan untuk tetap memperhatikan campuran warna yang ditampilkan agar tidak berbenturan dengan identitas perusahaan maupun informasi yang disampaikan. Perhatikan juga durasi video motion graphic agar tidak memberikan kesan bosan maupun membingungkan karena penggunakan transisi yang berlebihan.

5. Dalam tahap testing dan distribution disarankan untuk selalu aktif berdiskusi dan mencatat hasil terkait preview and testing serta mendokumentasikan hasil dengan rapi. Dokumen hasil preview tersebut bertujuan untuk mengingatkan client akan materi atau bagian yang akan direvisi dan bagian yang sudah disetujui.

\section{DAFTAR PUSTAKA}

Armstrong, M. (2002). Employee Reward. Wildside Press. CIPD Publishing.

Andrews, S. (2009). Human Resource Management. Tata McGraw.

Pirngadi, T. (2016). Majalah Fokus Bank Indonesia. Jalur Karier Sesuai Passion Edisi 31- 33. DSDM BI.

Baran, S. J. dan Davis, D. K. (2010). Teori Komunikasi Massa Dasar, Pergolakan, dan Masa Depan. Jakarta: Salemba Humanika.
Nuruddin. (2007). Pengantar Komunikasi Massa. Jakarta: Rajagrafindo.

Albig, W. (2007). Public Opinion. Read Books.

Satu, V. (2009). Panduan Belajar dan Evaluasi Sosiologi. Jakarta: Grasindo.

Boardman, A. (n.d.). What is Motion graphic. Retrieved from alboardman.

Gumelar, M.S. (2012). Academic Writing. Penerbit Lulu.com. pp. 55

Krishna, P., Machda, F. \& Syukri, J. (2010). Sejarah Motion graphic . History of Motion Design, pp. 5-6

Indonesian Motion Magz. (2010). Motion by Design. History of Motion Design.

Jones, D. (2013). Motion graphic Retrieved from Prezi: https://prezi.com/hxplssqvccjn/m otion-graphics

Kusrianto, A. (2006). Macromedia Flash Proffesional $8 . \quad$ Jakarta: Gramedia.

Shaw, A. (2015). Design for Motion: Motion Design Techniques and Fundamentals. Taylor \& Francis Group.

Rachmat, F. M. (2014). Rancang Bangun Media Promosi SMP Pius Cilacap. Jurnal Skripsi, pp. 7-8.

Darmayekti, G. (2007). Tracing Foto Menggunakan Gradient Mesh. Jakarta: Elex Media Komputindo. 